\title{
List of Plates
}

1. Gertrude Bulmer Bishop in front of Hill Home, Great Village, c. 1900.

2. Gertrude Bulmer Bishop and Elizabeth Bishop, c. 1913.

3. Elizabeth Bishop in front of Presbyterian Church.

4. Bulmer family home, Great Village.

5. Grace Bulmer Bowers (Aunt Grace), July 1956.

6. Marianne Moore by George Platt Lynes, c.1935.

7. Elizabeth Bishop and Louise Crane.

8. Elizabeth Bishop and Louise Crane, dockside.

9. Elizabeth Bishop outside her studio, Samambaia, Petropolis, Brazil.

10. Elizabeth Bishop, Lota and Aldous Huxley, Samambaia, Petropolis, 1958.

11. Elizabeth Bishop with camera on Amazon trip, 1960.

12. Elizabeth Bishop and Robert Lowell, Copacabana Beach, Rio de Janeiro. 


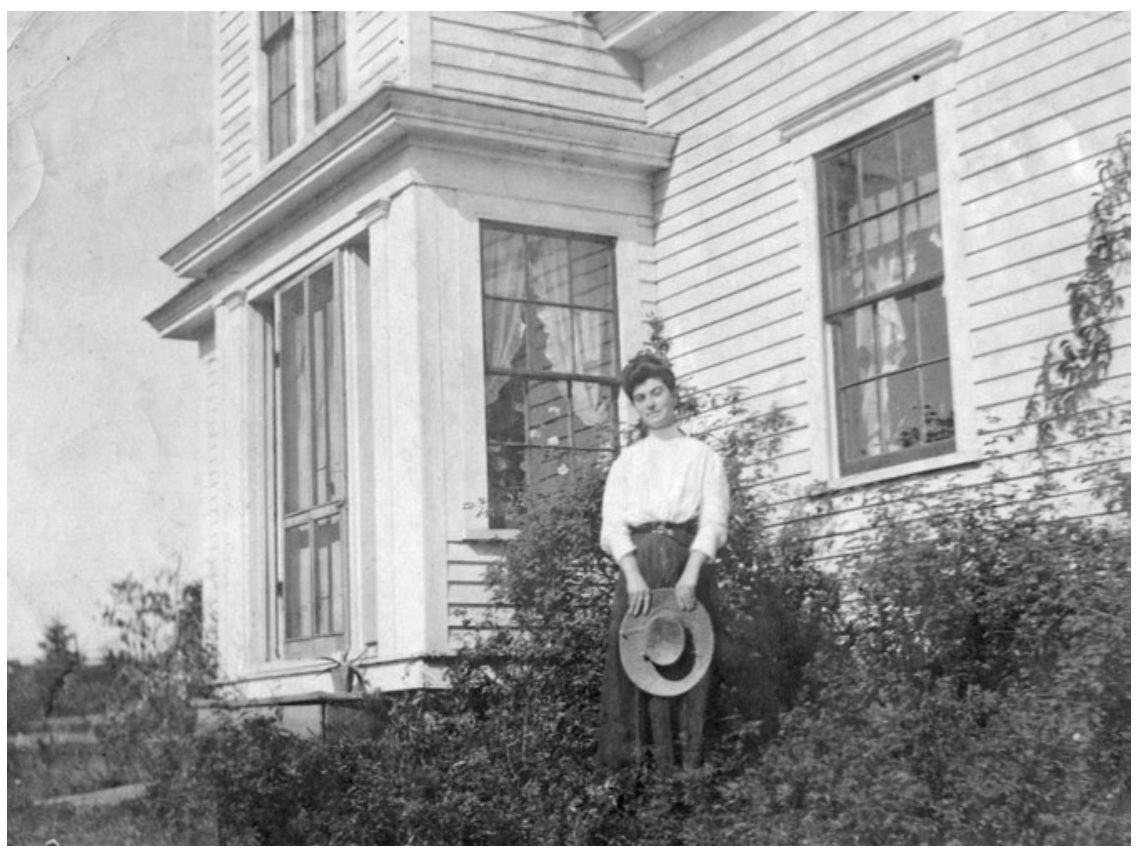

1. Gertrude Bulmer Bishop in front of Hill Home, Great Village, c. 1900.

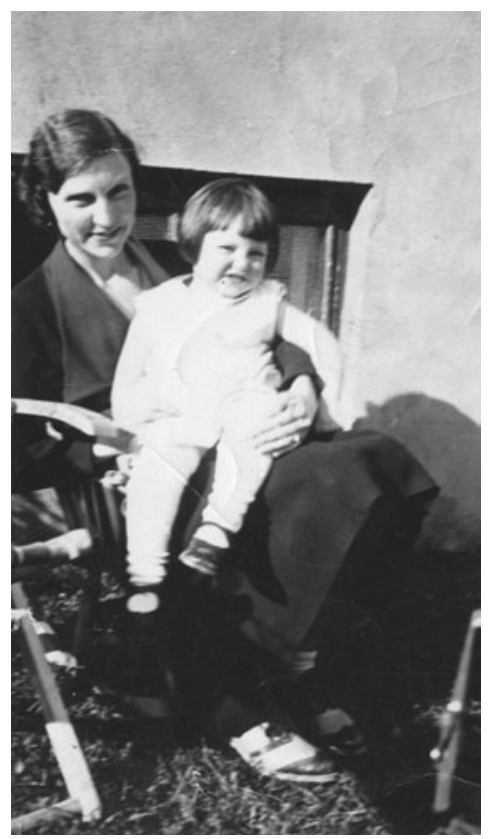

2. Gertrude Bulmer Bishop and Elizabeth Bishop, c. 1913. 


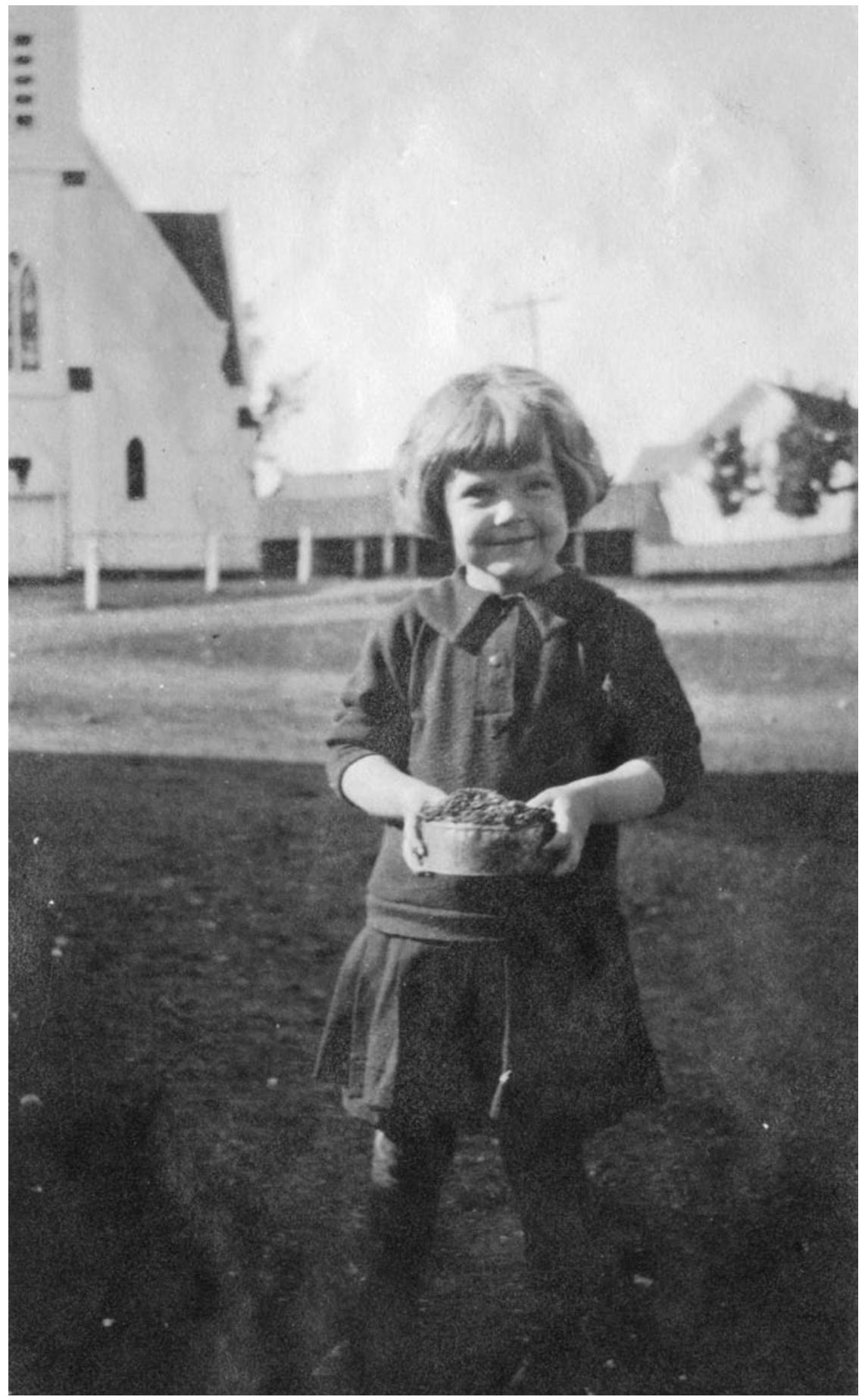

3. Elizabeth Bishop in front of Presbyterian Church. 


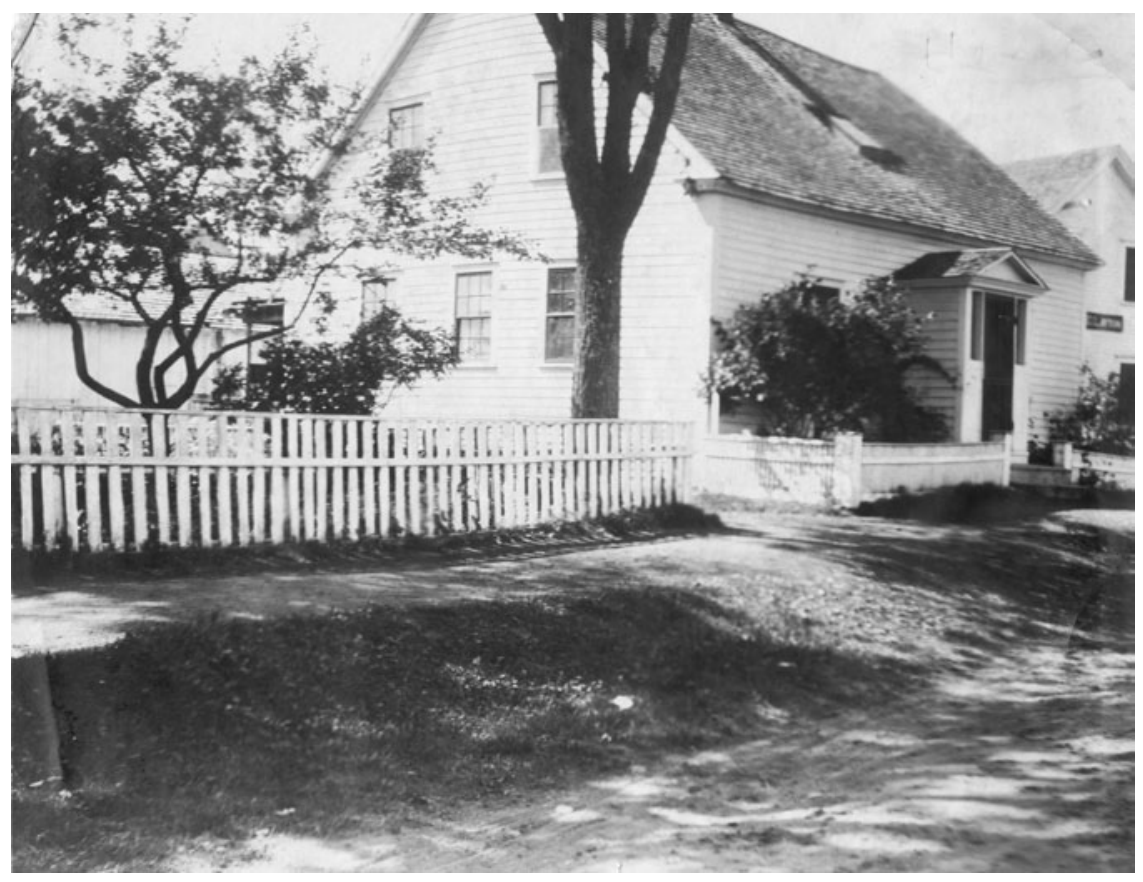

4. Bulmer family home, Great Village.

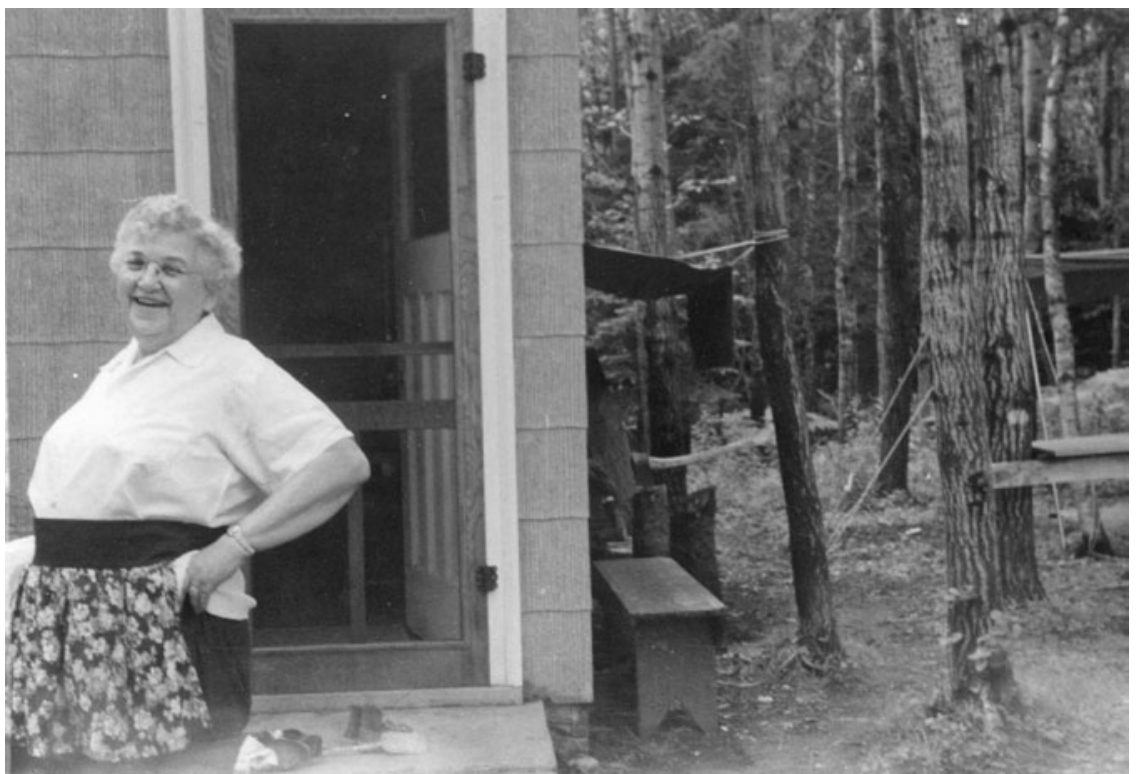

5. Grace Bulmer Bowers (Aunt Grace), July 1956. 


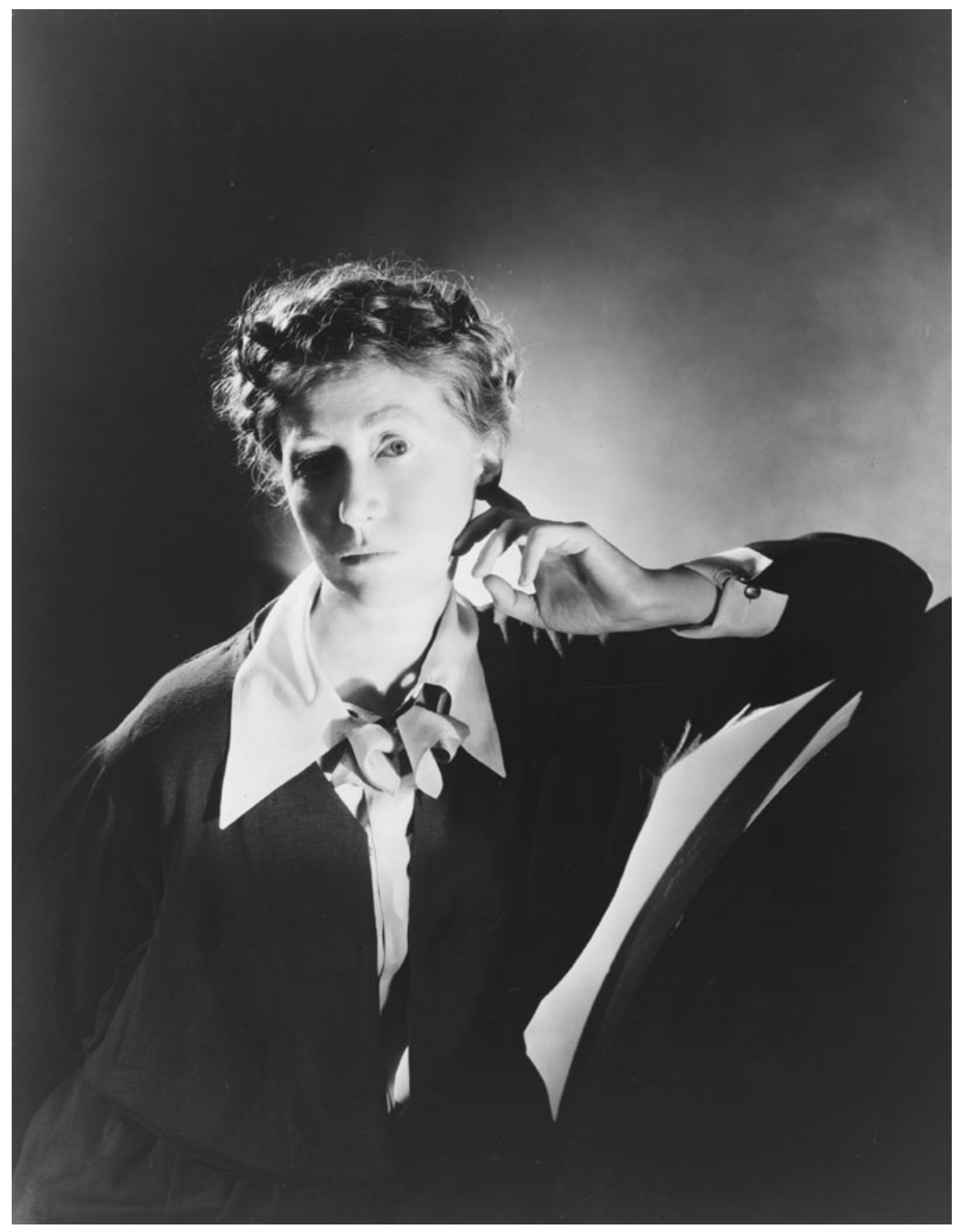

6. Marianne Moore by George Platt Lynes, c. 1935. 


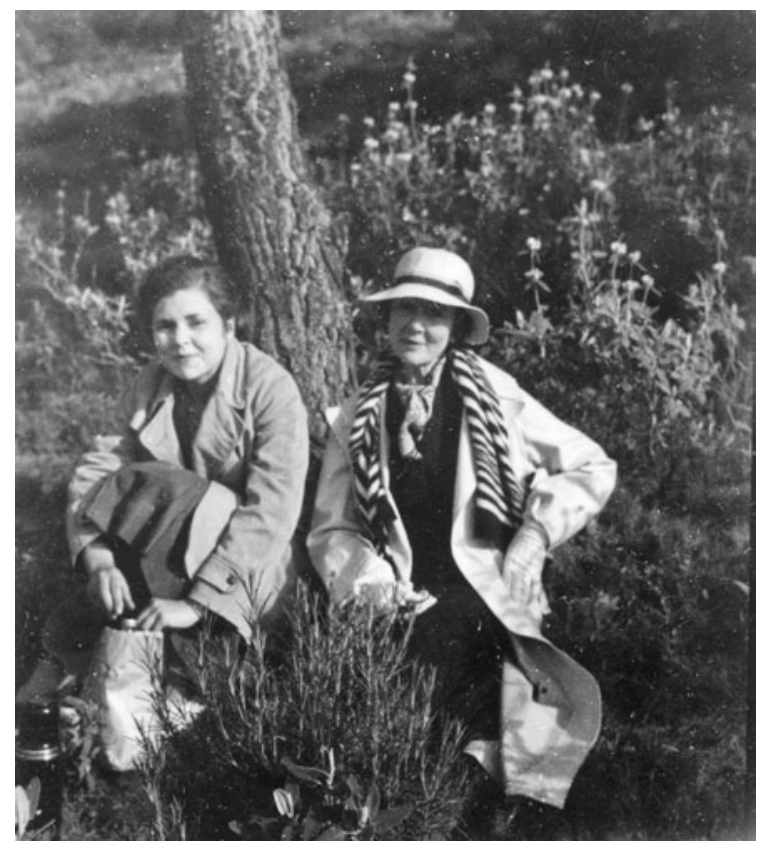

7. Elizabeth Bishop and Louise Crane.

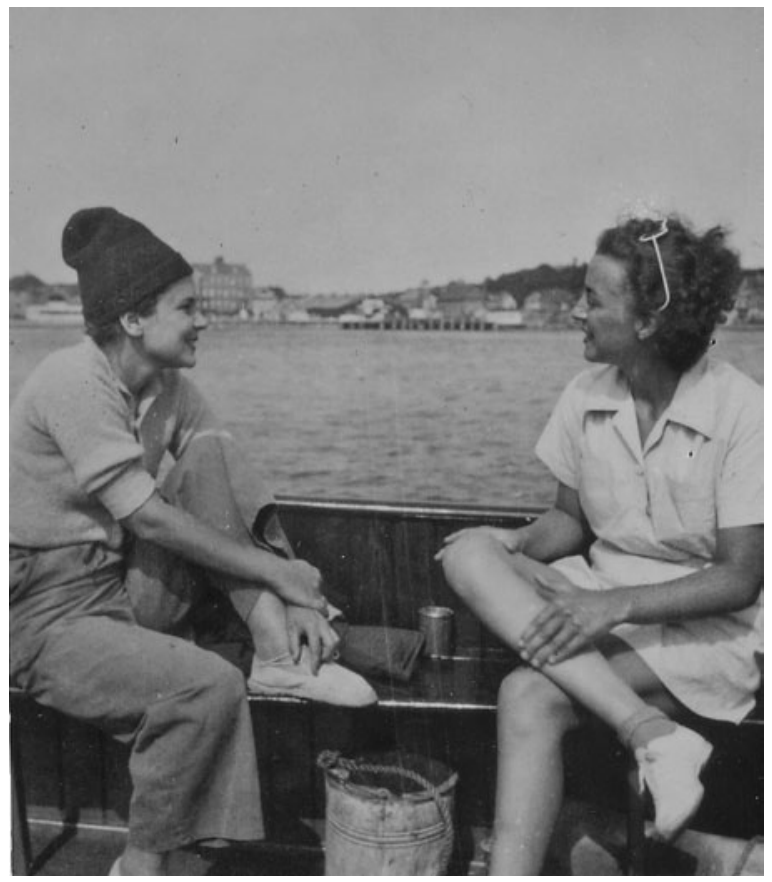

8. Elizabeth Bishop and Louise Crane, dockside. 


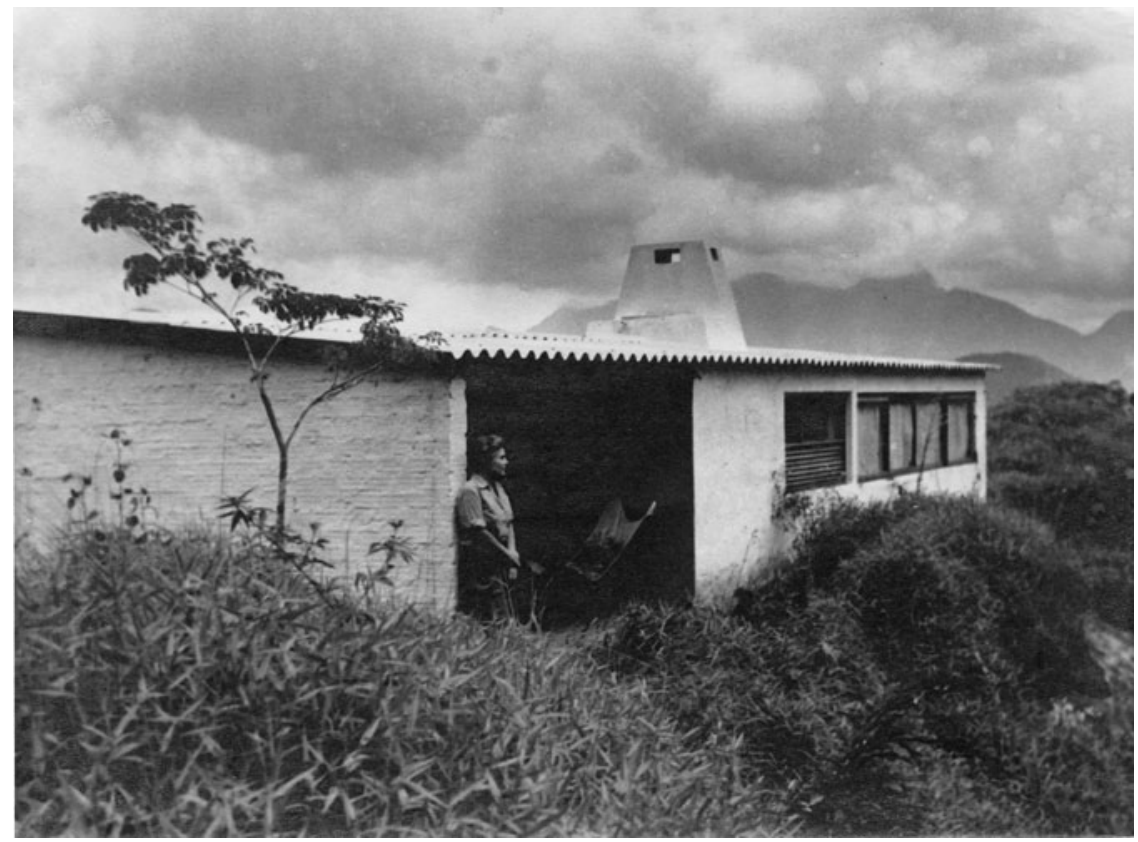

9. Elizabeth Bishop outside her studio, Samambaia, Petropolis, Brazil.

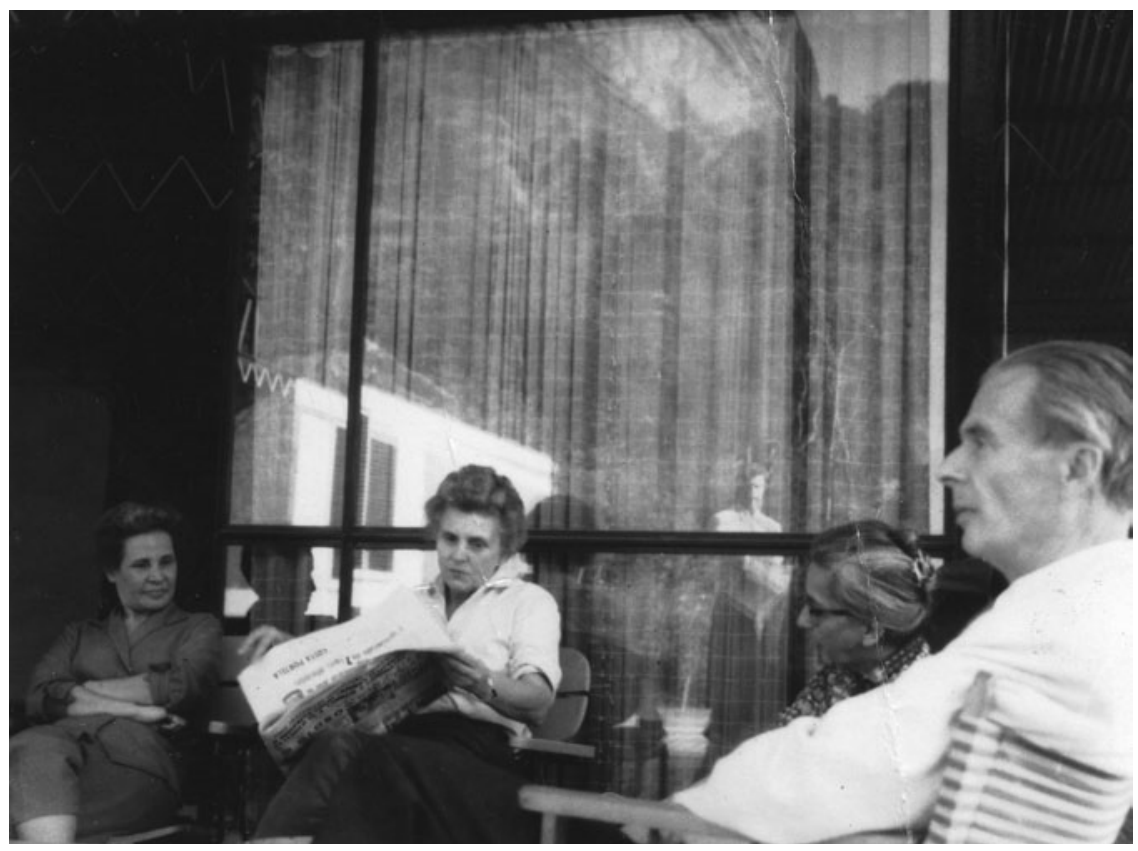

10. Elizabeth Bishop, Lota and Aldous Huxley, Samambaia, Petropolis, 1958. 


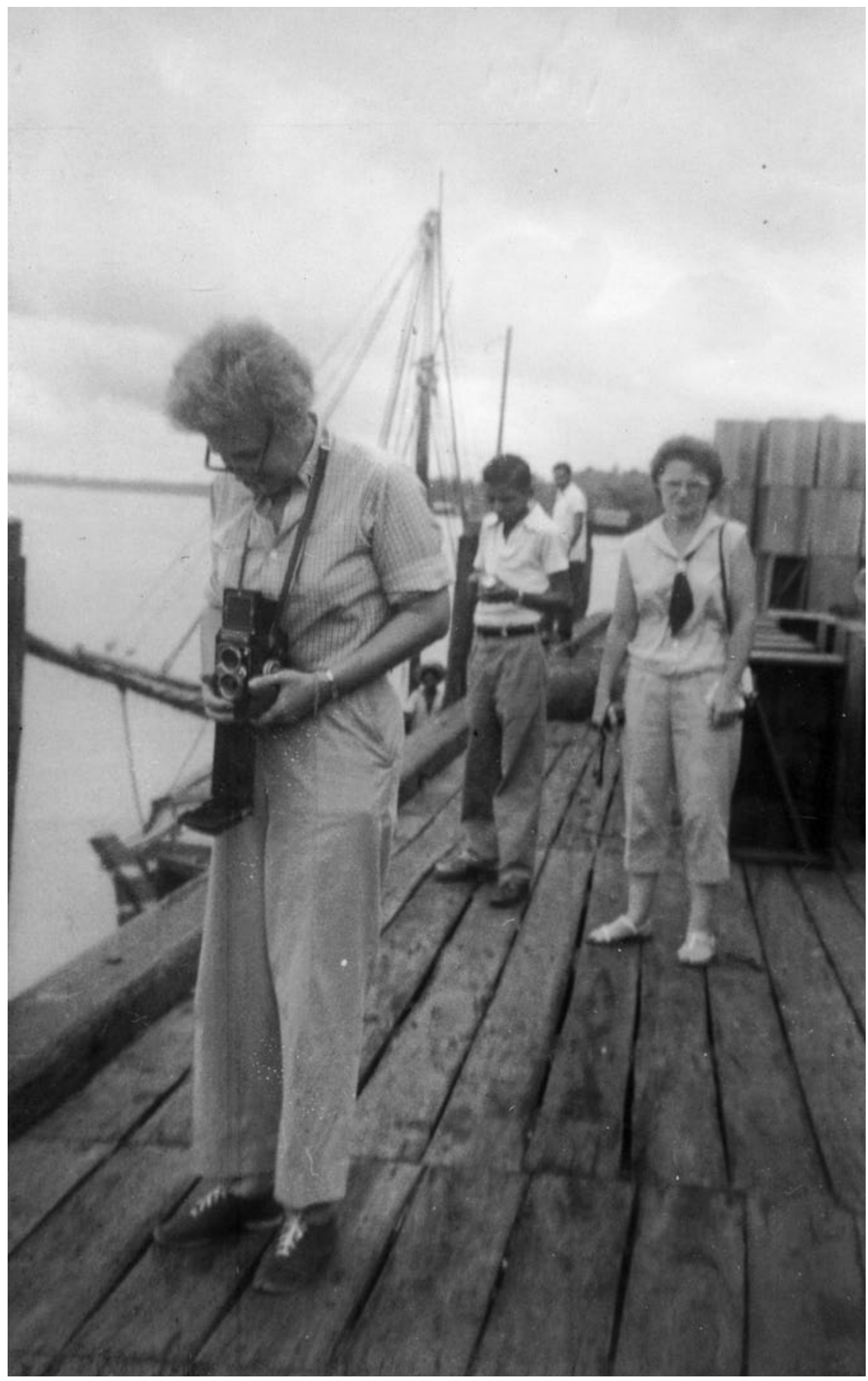

11. Elizabeth Bishop with camera on Amazon trip, 1960. 


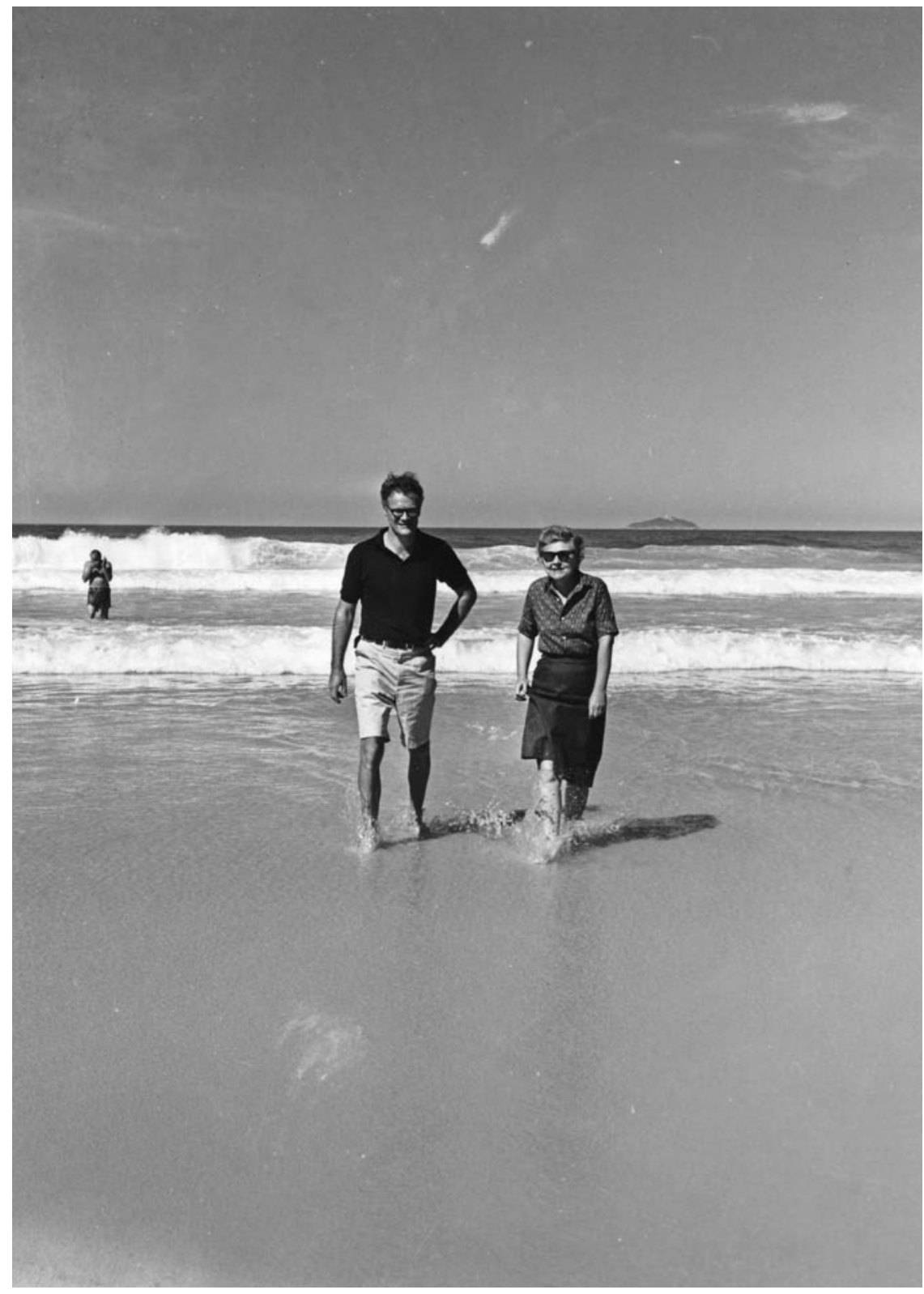

12. Elizabeth Bishop and Robert Lowell, Copacabana Beach, Rio de Janeiro. 